\title{
Experimental Investigation on Hydro-electric Steering system
}

\author{
S. J. Chikhale, P. R. Magdum, A. S. Rojole, N. A. Bagwan, T. U.Keskar, \\ A. P. Gadilkar, R. S.Apsunde \\ (Department of Mechanical Engineering, M. E. S. College of Engineering, S. P. Pune University, India)
}

\begin{abstract}
Today in the conventional power steering systems, it is observed that there are many drawbacks, such as it reduces the engine power in case of hydraulic power steering system, reduces mileage which leads to increased demand of fuels. This increases the operating cost. There is a need to develop such a system which enhances the engine performance and gives better result as of the conventional steering system. In hydro electrical power steering the hydraulic energy is produced by an electrically driven pump rather than a belt driven pump as in traditional hydraulic power assisted steering systems.
\end{abstract}

Keywords - Hydro-electric steering.

\section{Introduction}

The steering system is the key interface between the driver and the vehicle. The main requirement is that the steering should be precise, with no play. In addition, the steering system should be smooth, compact and light. It must also provide the driver with a perfect feel for the road surface and help the wheels return to the straight-ahead position. The standard steering arrangement is to turn the front wheels using a hand-operated steering wheel via the steering column. The steering column may contain several joints to allow it to deviate somewhat from a straight line. These joints may also be part of the collapsible steering column design to protect the driver in frontal crash situations.

\section{Background Theory}

Hydraulic steering system has been extensively applied in small type of loader and other engineering vehicles do to its special superority, how to forecast its dynamic behavior in design stage is most impotant problem [1] Mechanical steering system or Hydraulic Assisted Power Steering (HPAS) are no longer practical in EV application. This is due to a constant energy supply from battery is required to maintain the pressure in the hydraulic pump. It also requires regular maintenance to the hydraulic mechanism system. Meanwhile, EPAS system is only consumed energy when the steering wheel is turned. It also requires no liquid medium, fewer mechanical components, less fault tolerance and most importantly environment friendliness [2 - 4]. Fully electric vehicles with individually controlled electric motor drives provide significant benefits in terms of vehicle cornering response. In particular, the control of the left-to-right and front-to rear wheel torque distributions, also called torque-vectoring or direct yaw moment control, has been shown to be beneficial in: i) shaping the under steer characteristic (i.e., the graph of steering wheel angle against lateral acceleration) ${ }^{[5,6]}$ Several controllers have been proposed for the direct yaw moment control of fully electric vehicles with multiple motors, such as proportional integral derivative (PID) controllers running in parallel with non-linear feed forward contributions [5], linear quadratic regulators [7, 8], and various configurations of sliding mode control $[9,10]$, each of them with specific advantages and disadvantages. From the view point of the low-level controllers for all locating the wheel torques, some authors propose energy-efficient wheel torque distribution criteria for the generation of the reference yaw moment and total wheel torque demand $[2,11]$. The limitation of battery capacity has always been a major concern in electric vehicle (EV)[12]. Y.H. Li et al [13] Deals with the development of electro-hydraulic (EH) proportion control system for travelling and track-laying work in the track-laying machinery (TLM) for high speed railway construction. In this paper, we are presenting the work done on experimental investigation of hydro-electric power steering for hatchback car consisting rack and pinion mechanism. Further extending the work on steer ratio, minimized human efforts for steering and to increase the overall efficiency of the vehicle.

\section{Hydro-Electric Power Steering}

Hydro-Electric power steering systems with the universal motor unit on a second pinion are designed for earth moving and agricultural equipment's. The assist power is applied directly to the rack. This design allows for lower inertia, lower friction and more direct steering feel, as well as superior response. The physical separation of the sensor and the drive unit offers the opportunity for a performance-optimized configuration 
thanks to optimum use of the available installation space. Hydro-Electric power steering systems with paraxial drive are designed for high performance applications. They are characterized by low system friction and high efficiency. Due to the combination of rack and pinion gear and toothed belt drive, systems with paraxial drive are ideally suited for differing high performance requirements. The wide range of positioning possibilities of the servo unit allows optimum use of the installation space on the vehicle and helps to meet the highly demanding crash safety requirements of the automotive industry. In the past fifty years, car steering systems haven't changed much. But there will be significant advances in car steering in the next decades. Of particular interest is the introduction of "steer-by-wire" or "drive-by-wire" systems. Such systems completely eliminate the mechanical connection between the steering wheel and the steering mechanism at the wheel, replacing it with a purely electronic control system. The steering wheel will essentially only contain sensors that tell the car what the driver is doing, whereas some motors in the steering wheel will provide the driver with feedback on what the car is doing. The output of the sensors will be used to control a motorized steering system. "Steer-by-wire" will reduce the vehicle weight, free up space in the engine compartment by eliminating the steering shaft and also reduce vibration inside the car.

\section{Construction And Configuration}

In hydro-electric steering system motor is built in to the steering rack housing, making it most sophisticated and expensive type to hydro-electric steering system this type uses universal motor, with the armature mounted so that it actually rotates around the rack. At one end of the motor, a gear meshes with another gear to turn a pinion that is perpendicular to the rack. A clamp connects a pinion to the rack, so as the unit moves along the length of pinion; its motion is transferred directly to the rack. The steering wheel torque sensor is built inn to the pinion housing. This motor in rack layout has the advantage of being extremely compact. Constuctional view is shown in Fig. 1. A GI frame is constructed on which the hydraulic circuit comprising, a pump, fluid lines, valves and actuator is mounted. A DC motor is provided to drive the pump. The steering linkage to the rack is replaced by a universal motor, which steers the vehicle. Limiting switch or an angle sensor is fabricated which senses the amount of steering wheel steered by the driver. The universal motor and the DC motor are powered by a 12volt rechargeable battery. Schematic layout is shown in Fig. 2.

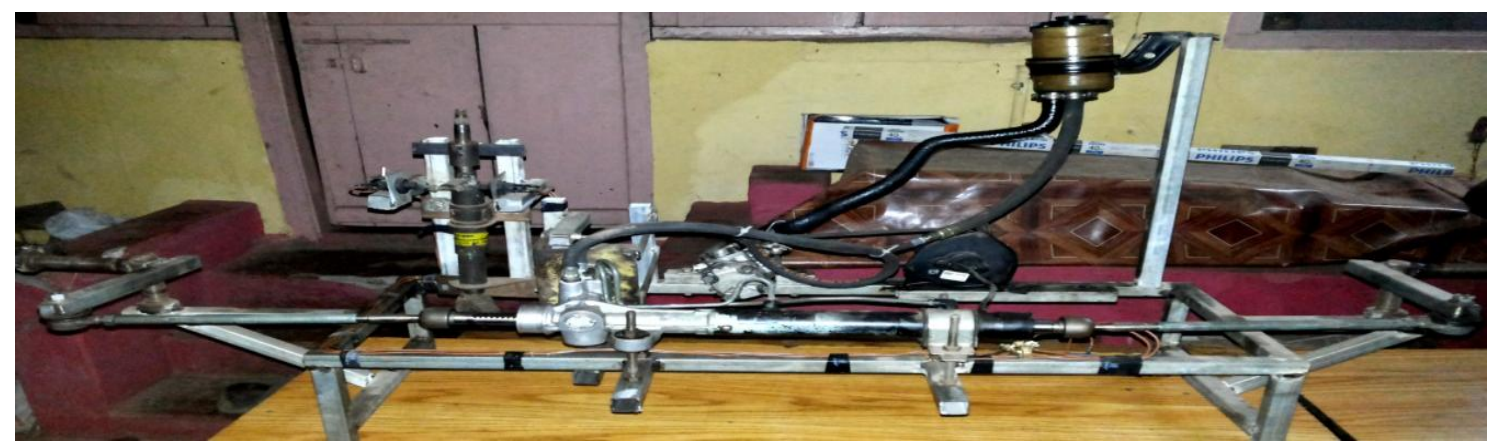

Fig. 1 Constructional view

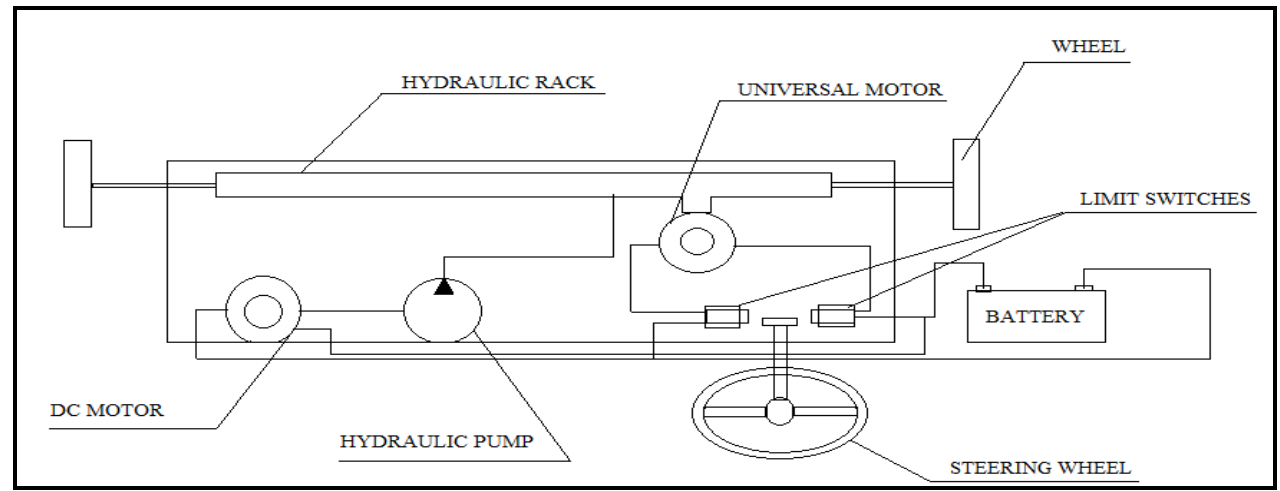

Fig. 2 Schematic layout of hydro-electric steering mechanism

\section{Control Strategy}

The steering control unit needs a lot of information to get the boost level and timing just right. Along with vehicle speed and charging system output level most of the other data is already available from several 
onboard computers. There is one new sensor required, a steering wheel torque sensor that tell the control unit how much effort the driver is applying to the steering wheel. In poorly designed systems, this can result in the vehicle oscillating or "yawing" around the center line as the driver attains to correct the over steer. In the new system, software allows precise control over steering behavior. Algorithms programmed in to the system define speed sensitivity, yaw damping and steering self-centering. Added algorithms can give steering a "sports" feel or offer light load setting. A safety relay incorporated in to the design improves fault tolerance, while ECU includes diagnostic functions for fault detection and management. If the system fails, "fail stop" design cuts or torque assistance and returns the driver to manual steering. The pressure required for the steering servo assistance, is produced by a hydraulic pump. This pump is driven directly by the vehicle engine, as in the conventional, familiar power assisted steering system .In other words, part of the engine power output is required for driving the pump.At the moment at which the greatest steering servo assistance is required mainly when parking - engine speed is at its lowest .The pump capacity is designed for such a case The faster the steering rate, the higher is the pump speed and thus the volume flow Pump capacity which is not required at higher engine speeds, is dumped via a bypass. In the new steering system, as Shown in Fig. 3, although the hydraulics likewise assist human steering effort ,the hydraulic pump - a gear pump - is driven in this case by an electric motor and is mechanically independent of the vehicle engine. The hydraulic control is of identical design. A new feature is the universal motor used to steer the vehicle i.e. a universal motor moves the steering rack which in turn steers the vehicle.

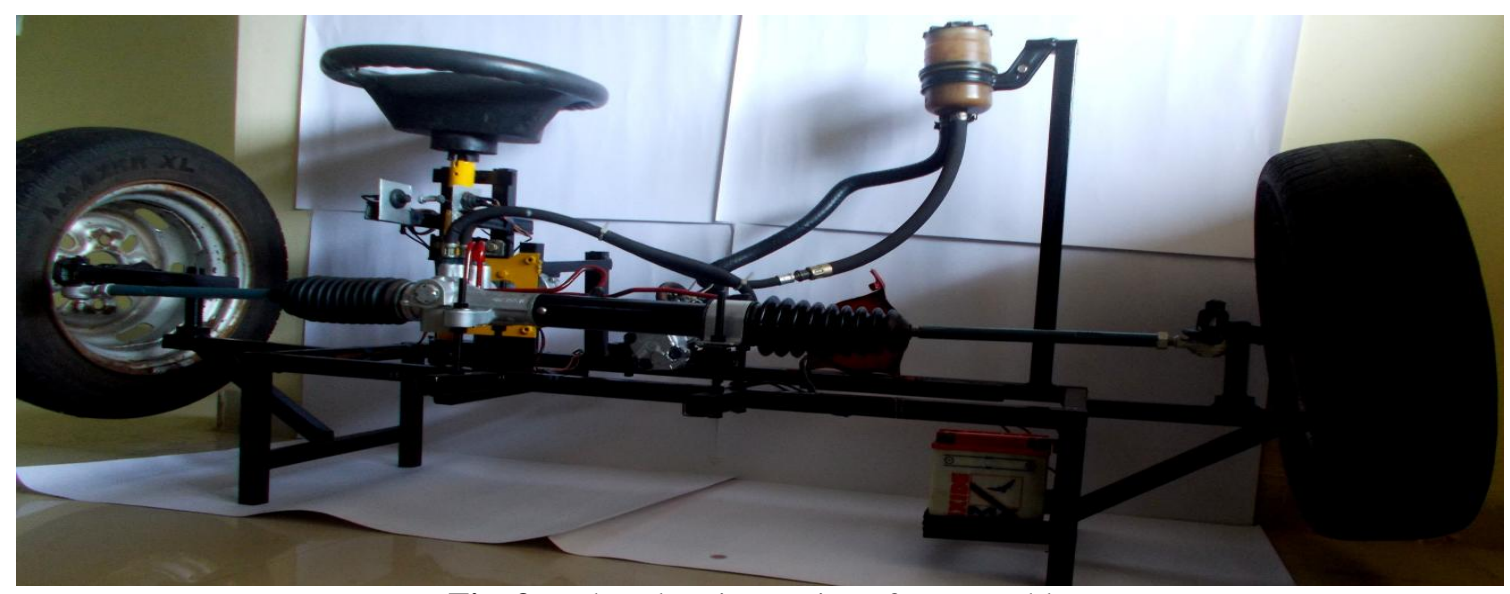

Fig. 3 Hydro-electric steering after assembly

\section{Results And Discussion}

The steering ratio of the system is calculated using holding time of steering wheel and angle of turning of the tire. The maximum steering wheel deviation that can be achieved is $20^{\circ}$ due to the limit switches. The steering wheel thus can deviate up to $20^{\circ}$ and hence thus holding time can be calculated. Following formula is used to calculate steer ratio:-

Steering ratio $=$ Degree of turning $/$ Holding time of the Steering Wheel

Right side turn

Steering ratio $=17 / 2.5=6.8$

Average $=(6.5+6.8+7.33+7.25+7.4) / 5=7.056$

Left side turn

Steering ratio $=18 / 2.5=7.2$

Average $=(7+7.2+7.33+7+7.4) / 5=7.186$

Table 1 Rright side turn

\begin{tabular}{|c|c|c|c|}
\hline Sr.no. & $\begin{array}{l}\text { Holding } \\
\text { Time(s) }\end{array}$ & $\begin{array}{l}\text { Turn } \\
\text { Angle(deg.) }\end{array}$ & $\begin{array}{l}\text { Steering } \\
\text { Ratio }\end{array}$ \\
\hline 1 & 1 & 6.5 & 6.5 \\
\hline 2 & 2.5 & 17 & 6.8 \\
\hline 3 & 3 & 22 & 7.33 \\
\hline 4 & 4 & 29 & 7.25 \\
\hline 5 & 5 & 37 & 7.4 \\
\hline
\end{tabular}

Table 2 left side turn

\begin{tabular}{|c|c|c|c|}
\hline Sr.no. & $\begin{array}{l}\text { Holding } \\
\text { Time(s) }\end{array}$ & $\begin{array}{l}\text { Turn } \\
\text { Angle(deg.) }\end{array}$ & $\begin{array}{l}\text { Steering } \\
\text { Ratio }\end{array}$ \\
\hline 1 & 1 & 7 & 7 \\
\hline 2 & 2.5 & 18 & 7.2 \\
\hline 3 & 3 & 22 & 7.33 \\
\hline 4 & 4 & 28 & 7 \\
\hline 5 & 5 & 37 & 7.4 \\
\hline
\end{tabular}

Time required to turn from extreme right to left $=10.6 \mathrm{sec}$ 
Relation between time required and wheel turn angle for right and left side turn is shown in Fig 4.

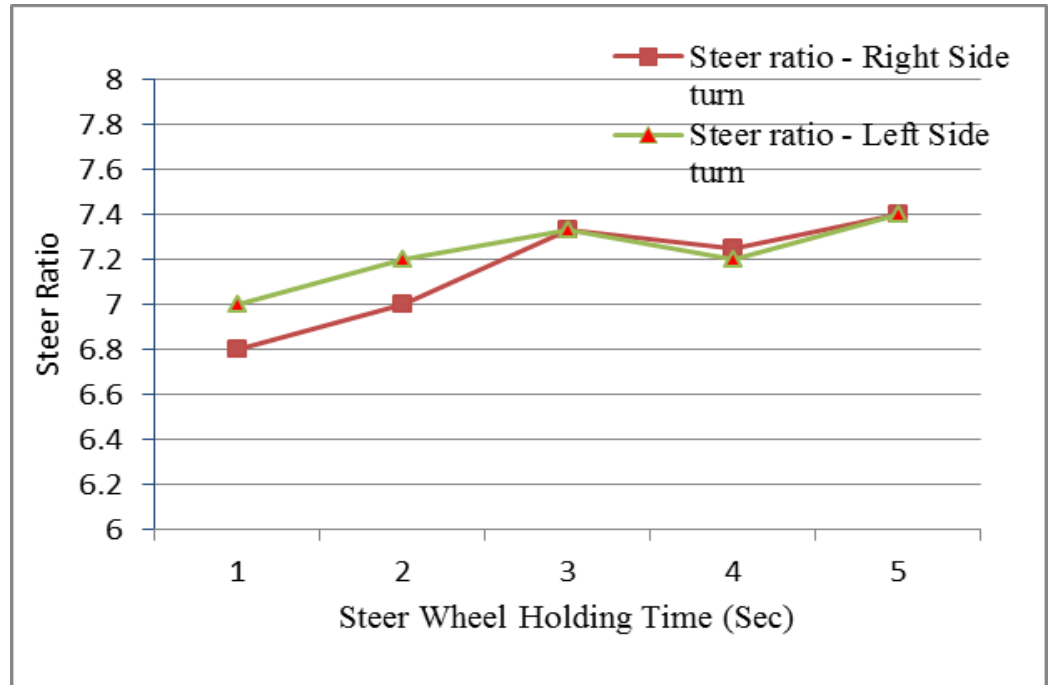

Fig. 4 Relation between time required and wheel turn angle for right and left side turn

Fig. 4 shows that the holding time required turning the vehicle on right and left side is identical, thus steering system is balanced on both sides. From Fig. 5, it is seen that steer wheel holding time and steer ratio plot for both right and left side turn shows closed match.

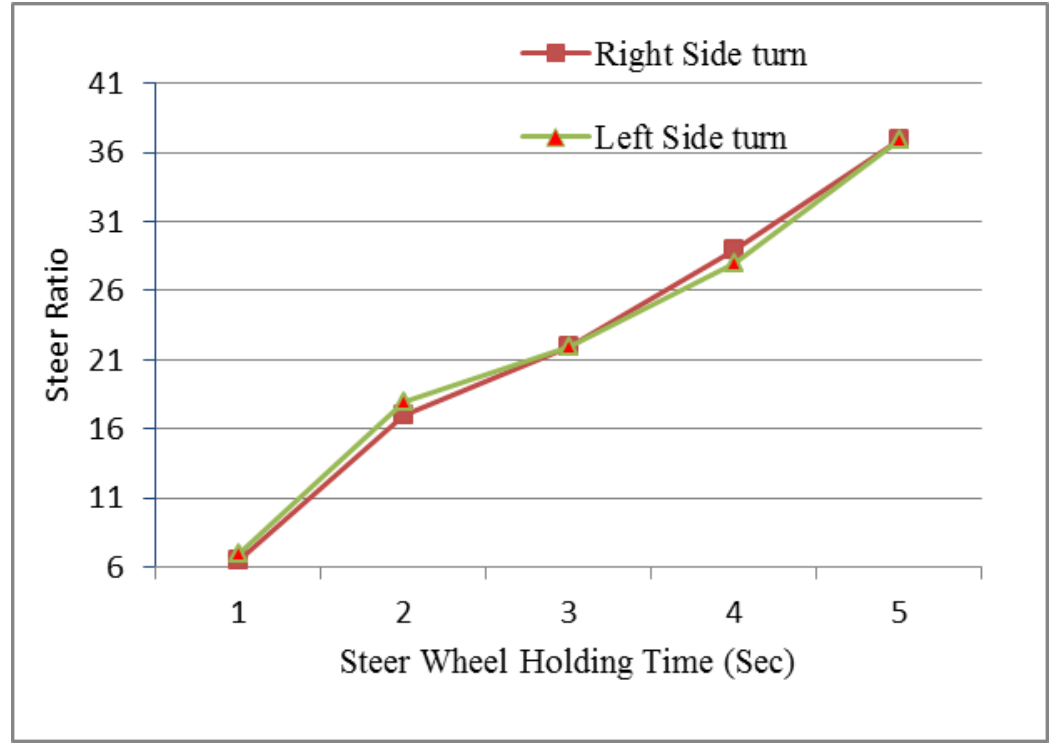

Fig. 5 Steer wheel holding time and steer ratio plot

VII. Conclusion

From the experimental investigation and observation table, the model is reliable in any working condition. Its construction is simple. Improvements in comfort through reducing driver effort, easier operation when parking under low speed, whilst maintaining taught steering when driving at high speeds. The hydraulic energy is now produced by an electrically driven pump rather than a belt driven pump as in traditional hydraulic power assisted steering systems. Therefore, engine power can now be used to move the vehicle rather and power minimal ancillaries / auxiliaries via the drive belt.

\section{References}

[1] Gong youpinga, Bian xiangjuanb ,Chen guojina,Multi-Functional Loader Steering Hydraulic System model construction and simulation Based on Power Bond Graphs,Procedia Engineering 15 (2011) 358 - 364

[2] Dariusz Z. 2011. Modelling of EPS Type Steering Systems Including Freeplay and Friction in Steering Mechanism. Journal of KONES Powertrain and Transport, Vol 18.1. pp 689-696. 
[3] Xin L, Xue P.Z.and Jie C. 2009. Controller Design for Electric Power Steering System Using T-S Fuzzy Model Approach. International Journal of Automation and Computing. 6(2). pp 198-203.

[4] Chunhua,H. 2008. Modelling and Simulation of Automotive Electric Power Steering System. IEEE Second International Symposium on Intelligent Information Technology Application. pp 436-439.

[5] L. DeNovellis, A.Sorniotti, P.Gruber, J.Orus, J.M.Rodriguez Fortun,J.Theunissen, J.DeSmet, Direct yaw moment control actuated through electric drive trainsand friction brakes: theoretical design and experimental assessment, Mechatronics 26 (2015) 1-15.

[6] L. DeNovellis, A.Sorniotti, P.Gruber, Wheel torque distribution criteria for electric vehicles with torque-vectoring differentials, IEEETrans. Veh.Technol.63(4)(2014)1593-1602.

[7] E. Esmailzadeh, A.Goodarzi, G.R.Vossoughi, Optimal yaw moment control law for improved vehicle handling, Mechatronics 13 (2003) 659-675.

[8] M. Mirzaei, A new strategy for minimum usage of externally awmoment in vehicle dynamic control system, Transp. Res. Part C18 (2010) 213-224.

[9] M. Canale, L.Fagiano, A.Ferrara, C.Vecchio, Vehicle yaw control via second-order sliding-mode technique, IEEE Trans. Ind. Electron. 55 (11) (2008) 3908-3916.

[10] T.Goggia, A.Sorniotti, L.DeNovellis, A.Ferrara, P.Gruber,J. Theunissen, D.Steenbeke, B.Knauder, J.Zehetner, Integral sliding mode for the torque- vectoring control of fully electric vehicles: theoretical design and experimental assessment, IEEETrans. Veh.Technol. 64(5) (2015) 1701-1715.

[11] Y.Chen, J.Wang, Adaptive energy-efficient control allocation for plan a motion control of over-actuated electric ground vehicles, IEEE Trans. Control

[12] Dariusz Z. 2011. Modelling of EPS Type Steering Systems Including Freeplay and Friction in Steering Mechanism. Journal of KONES Powertrain and Transport, Vol 18.1. pp 689-696.

[13] Y.H. Li et al., Development of electro-hydraulic proportion control system of track-laying machinery for high speed railway construction, Mechatronics (2016). 